\title{
MÍMESIS COLONIAL Y MÍTICA EN COLACHO HERMANOS O PRESIDENTES DE AMÉRICA DE CÉSAR VALLEJO
}

\author{
Colonial and mythical mimesis in Colacho Hermanos o Presidentes de \\ América by César Vallejo
}

\author{
Jorge Luis Yangali Vargas ${ }^{1}$
}

\begin{abstract}
RESUMEN
En el presente ensayo, se analiza la lógica mimética en la dramaturgia de César Vallejo. Se trata de una aproximación al más emblemático de sus textos teatrales: Colacho Hermanos. Estructuralmente, primero se aborda el dramatis personae de la pieza y se señala los rasgos de los dos principales personajes de la misma: los hermanos Mordel y Acidal. Luego, se trabaja los sentidos que adquiere la mímesis, mítica y colonial, en la que se ven incursos los personajes. Finalmente, ya situado en la lógica mimética colonial del poder, se analiza la idea con la que termina la pieza de Vallejo: fin a la farsa. Mímesis colonial, que desde la perspectiva vallejiana, caracterizó a la clase política latinoamericana servil al imperio.
\end{abstract}

Palabras clave: Vallejo, Colacho Hermanos, mímesis, colonialidad, mythos.

\begin{abstract}
In the present essay we analyzed the mimetic logical in the dramaturgy by César Vallejo. It is an approach to the most emblematic of his theater play: Colacho Hermanos. Structurally, first the dramatis personae of this piece is approached and the features of the two main characters of it are pointed out: the brothers Mordel y Acidal. Then, we work on the senses that acquire the mimesis, mythical and colonial, in which the characters are involved. Finally, already it located in the colonial mimetic logic of power, the idea is analyzed with which Vallejos's play ends: farce finishes. Colonial mimesis, which from the Vallejo perspective characterized the Latin American political class servile to the empire.
\end{abstract}

Key Words: Vallejo, Colacho Hermanos, mimesis, coloniality, myths.

\footnotetext{
${ }^{1}$ Universidad Nacional del Centro del Perú, investigador y docente de literatura. Perú.

Correo electrónico: yanlivargas@hotmail.com

Recepción: 23-08-2017. Aceptación: 01-11-2017.
} 


\section{Introducción}

Partamos escolásticamente recordando el argumento de Colacho hermanos: en esta farsa dos mellizos cuarentones, Mordel y Acidal, tienen un ascenso social y político vertiginoso. De ser obreros y pequeños comerciantes en la pequeña aldea andina de Taque, pasan a administrar el proceso de tercerización para contactar y “contratar" a los indígenas obreros para la minera aurífera "Cotarca Corporation". Al mismo tiempo que ofrecen su servicio de contratación de personal a la empresa minera, continúan acrecentando su negocio de víveres y mercancías en el pueblo que, de ser una "tienducha", se transformó en un "gran bazar".

La pieza vallejiana, en ese sentido, da cuenta del progresivo aburguesamiento de los miembros de una clase de origen marginal, cuyo principal "negocio" o próspero comercio es traficar o vender la fuerza de trabajo de los indígenas, ${ }^{2}$ negocio que cuenta con el apoyo político y militar, representados por el Gobernador y el Comisario. En fin, en su obra, Vallejo presenta un orquestado sistema de explotación de la fuerza indígena. La presencia del modo imperialista de explotación, la discriminación social, la expoliación sexual de la servidumbre entre otros rasgos o tópicos argumentales que ofrece la pieza vallejiana, de acuerdo con Ballón (1988, p. 437), no habían sido abordados por ningún otro dramaturgo peruano de los años 30 .

Antes de continuar, se destaca el concepto de mímesis que José Ramón Alcántara propone a partir de los hallazgos filológicos de Northop Frye (1977) y Paul Ricoeur (1995). El crítico mexicano distingue la mímesis platónica -quien la entiende como equivalente a imitación- de la mímesis aristotélica, entendida por el estagirita como representación:

Es decir, construcción, cuyo propósito no es imitar sino inscribir en el material una dimensión de significado que remita no a la naturaleza (lo que sería imitación) sino a aquello que está en el fundamento de la naturaleza real que es el Mythos (Alcántara, 2002, p. 57).

Entendiéndose Mythos como la dimensión de la realidad que tiene que ver con el acto de narrar las pasiones y acciones humanas, entre ellas el goce estético.

\footnotetext{
${ }^{2}$ El aburguesamiento de los Colacho es progresivo y de acuerdo con el dramatis escenarium se ve expresado en las modificaciones del escenario que va de decorados rústicos en el primer acto a decorados lujosos en el tercer y último acto. De vivir en Taque, una aldea andina, a morar en la casa política capitalina de los Colacho.
} 


\section{Los Colacho se enriquecen}

Repasado el argumento y los supuestos teórico-metodológicos, se pasa a conocer a los personajes protagonistas de la farsa. La acumulación de bienes por parte de los Colacho los va enriqueciendo y, al mismo tiempo, sujetando al autor material de su prosperidad: el imperio norteamericano, que en los dos primeros actos de la obra está representado por Tenedy ("un norteamericano acriollado"). ${ }^{3}$ Tenedy es un hábil gerente minero que impone su autoridad económica imperial por encima de la autoridad política local, tanto que, en la obra, él es quien tiene la capacidad o atributo de asignar, mediante su apoyo económico o uso de influencias, los principales cargos políticos y de gobierno: el de gobernador en Taque, el de diputado regional (de Cortes) e incluso, como lo hace con Mordel Colacho, el de presidente de una anónima república americana.

Siguiendo a Estermann, se diría que Vallejo ofrece un vínculo colonial entre los hermanos Colacho y Tenedy. De acuerdo con Estermann, colonialidad, en el sentido económico y político, se entiende como reflejo de la dominación del sector extractivo, productivo, comercial y financiero de los estados y sectores colonizados por parte de los países industrializados; lo que lleva a la dependencia, subdesarrollo, sub-alternidad y marginalidad de las colonias frente al dominio de los imperios dominadores (Estermann 2014 , p. 3). En el terreno de la representación política y cultural, la colonialidad no tiene que ver con que todos somos producto del proceso humano de la inter-trans-culturación -que es un hecho histórico-, sino con el vínculo que establece de este fenómeno con la “involuntariedad, dominación, alienación y asimetría de estructuras políticas, injusticia social, exclusión cultural y marginación geopolítica” (Estermann, 2014, p. 3).

La literatura antiimperial y en especial la "antiyanqui”, según Klein (1973), tiene que ver con el triunfo de la América inglesa frente al alicaído imperio español de fines del siglo XIX. En esta línea de escritura, algunos escritores antiimperialistas siguieron el credo “arielista” sugerido por José Enrique Rodo, quien valora el legado criollo deudor de la cultura española; en especial, de la lengua española. ${ }^{4}$ La literatura antiimperial latinoamericana tiene

\footnotetext{
${ }^{3}$ De aquí en adelante cito a "Colacho Hermanos" de Tres obras dramáticas (1996).

${ }^{4}$ Un caso vigente y actual por la defensa de la lengua española en territorio de administración norteamericana es la sostenida por el pueblo puertorriqueño. La literatura contra el imperio yanqui es basta, en especial, en Centroamérica. Destacan textos producidos en Panamá, Cuba, Costa Rica, Honduras, Nicaragua, México, Haití, etc. y autores como Rubén Darío, Américo Lugo, José Antonio Ramos, José de Diego, Carlos Gagini, Jorge Icaza, César Vallejo, entre muchos otros. Kosel, Grossi y Moroni dividen el imaginario antiimperialista, y dentro de él la expresión literaria, en América Latina en dos épocas: una
} 
que ver con la crítica a la moral estadounidense que, bajo el discurso proteccionista, ha ocultado y justificado acciones intervencionistas violentas, la mayor de las veces con un marcado racismo (Klein, 1973, pp. 212, 214 y 222). Se critican los monopolios yanquis como el petrolero, el bananero, etc.- que absorben las economías nacionales y, en consecuencia, manipulan las decisiones políticas. También se critica la ambición expansionista del imperio que operó extraterritorialmente mediante "contratos de concesión", otorgados por los gobernantes nacionales de turno que en los años 20 y 30 del siglo XX estaban representados por oligarquías criollas tradicionalmente subordinadas al poder imperial (español o norteamericanas).

La postura vallejiana es antimperialista en Colacho hermanos y Tungsteno $(1931) ;^{5}$ no obstante, su postura no es solo rechazar la presencia gringa en territorio latinoamericano, sino de toda forma de colonización. Si bien la producción vallejiana se produce cuando en Centroamérica se producía "un relajamiento de [la] agresividad" antiyanqui" (Klein, 1973, p. 210), debido a señales de "buena vecindad" planteadas por los gobernantes americanos. Postura de Vallejo que se entiende por el lugar desde donde enuncia su discurso: una Europa que vive la creciente euforia e incertidumbre ante el devenir de la revolución de 1917. Como se verá más adelante, la narrativa y dramaturgia antiimperial de Vallejo se diferencia del nacional patriotismo centroamericano sin dejar, por ello, de ser anticolonialista.

La descripción que realiza Vallejo, en el dramatis personae, de los dos personajes centrales pone el dedo en la piel y anticipa un rasgo colonialista: “Acidal y Mordel, tipos mestizos de indígena y español, siervos de origen, son actualmente obreros de albañilería, que ambicionan transformarse en comerciantes, partiendo de unos cuantos pesos economizados de sus jornales" (Vallejo, 1996, p. 24). Los rasgos descritos se pueden agrupar en aquellos que hablan de un tiempo presente y aquellos que se remontan a un pasado. Los rasgos presentes, en la pieza, son los que finalmente serán llevados a escena y, por lo tanto, identificar su performatividad en el escenario no ofrecerá a los espectadores ninguna dificultad: lo físico marcado por lo "mestizo"; lo laboral pautado por sus trabajos iniciales:

\footnotetext{
primera que va de 1898-1954, la cual recoge la postura de los intelectuales frente a la intervención americana; y la segunda abarca el periodo de las revoluciones, específicamente, de 1959 a 1990.

${ }^{5}$ Sobre la novela El Tungsteno, de César Vallejo, y su relación con el antiimperialismo, véase el estudio realizado por Ana María Vara (2013). Novela ambientada en un escenario minero semejante al primer acto de Colacho hermanos y narra la presencia norteamericana en las minas de tungsteno en el pueblo imaginario cuzqueño de Quivilca. Otro estudio significativo sobre la misma novela es el realizado por Julio Aldana Hidalgo (2016).
} 
“albañiles" y "comerciantes". Pero aquel rasgo que se remonta al pasado -"siervos de origen"- habla de un sistema mimético distinto. Se trata de un alto grado de vinculación mimética con el pasado no solo en lo epidérmico sino, y sobre todo, en lo histórico y, por ende, con la estructura política que signa su servidumbre ontológica: la colonia.

Otros rasgos, que se encuentran en la caracterización que Vallejo realiza de Acidal, serían: "retaco, muy gordo, colorado y sudoroso. El pelo negro e hirsuto [...] vestimenta pobre y hasta rotosa [...] frisa la cuarentena" (Vallejo, 1996, p. 25). Rasgos que también se pueden atribuir a Mordel a partir de la didascalia con la que Vallejo lo describe antes de su ingreso a escena: "Mordel Colacho entra por el foro, de prisa y malhumorado. Mordel es hermano mellizo de Acidal, con quien tiene un asombroso parecido, físico y moral. Su vestimenta es tan pobre como la de Acidal" (Vallejo, 1996, p. 27-28). Parecido físico que será decisivo en el intercambio de roles que ambos ejecutaran cuando se encuentren en el sillón de la presidencia de la República.

La actitud servil de los hermanos es estructural y ontológica. Pese a su ascenso social y hasta político a partir del segundo cuadro del primer acto y los subsiguientes, segundo y tercer acto, constituirá un impedimento para su actuar autónomo y moderno. Por ello, su condición social y ubicación laboral subalterna en el primer cuadro del primer acto de la obra hace que ellos no se encuentren en la escala más baja de la pirámide social; ubicación en la que sí se encuentran "numerosos campesinos y pastores indígenas”, con quienes los Colacho trafican y a quienes, además, les “compran” sus bienes y propiedades.

\section{Intercambio económico desde la colonialidad}

Un negocio colateral al tráfico de la fuerza laboral que tienen los Colacho es el de la adquisición de productos y propiedades, que en la obra se materializa en la compra de huevos, terrenos, con todo y siembra, y las casas de los indígenas. Compras, todas ellas, sostenidas en engaños y atropellos frente a la ignorancia o analfabetismo de la población. ${ }^{6}$ Veamos una de estas transacciones económicas ejecutadas entre los hermanos Colacho y los indígenas de Taque. Se trata de un caso especial: una pareja que trueca su terreno de trigo por dos garrafas.

\footnotetext{
${ }^{6}$ Georgette Vallejo (2012) reseña la labor de ayudante de contabilidad que cumplió César Vallejo en 1912 en la hacienda azucarera "Roma" donde, a decir de Georgette, César Vallejo pudo observar la explotación de "pobres criaturas [que] han sido salvajemente capturadas por siniestros 'enganchadores', y cobardemente retenidas por vida con el alcohol que, dominicalmente y con deliberada intención, se les vende a crédito” (p. 8).
} 
Una pareja de indígenas ingresa al bazar de los Colacho para adquirir una garrafa pintada que se supone ya vieron antes de esta visita y que están dispuestos a adquirirlo a cambio de concederle a Mordel Colacho un terreno sembrado de trigo:

MORDEL, mostrándoles a la luz y en alto las garrafas de colores: ¡Mirad lo que es preciosura! [...] ¿Veis las gallinas con sombrero que hay aquí pintadas? [...]

LOS DOS INDÍGENAS, considerando maravillados las garrafas: ¡Patrón, es tan precioso!...

MORDEL: ¿Verdad que son preciosas? En esta otra, más grande, hay unos árboles de oro, con gendarmes en las hojas. ¡Mirad la maravilla! ¡Aproximaos! ¡Más! [...] ¡Cogedlas, sin miedo, muchachos! (Pone una garrafa en manos del hombre) ¡Tómala! ¡De aquí! ¡Fuerte!...

EL HOMBRE, con la garrafa en la mano, intimidado: ¡Patrón!... ¡Patrón!... (Vallejo, 1996, pp. 53-54).

Luego, Mordel seguirá seduciéndolos y provocando el deseo de adquirir la garrafa, la cual propondrá vender y como pago recibir el terreno de trigo. Después de un momento de indecisión por parte del indígena y seducción de Mordel (el negociante), quien está confabulado en la venta con el Comisario del pueblo (quien durante toda la escena ríe ante la seductora venta e inocencia de la pareja), el indígena terminará corriendo "a besar la mano de Mordel" y a aceptar el intercambio:

MORDEL: Toma, muchacho, tu garrafa. Agárrala fuerte. ¡Con cuidado! No la vayas a soltar. (El hombre levanta la garrafa a la altura de sus ojos y así la lleva, como un sacerdote la hostia consagrada) [...] Ven... paso a paso... Por aquí... Poco a poco... Así... Así... (La mujer sigue el paso a su marido. Mordel parando al hombre bruscamente) ¿Cuándo me entregas el terreno?

EL HOMBRE: Cuando te parezca, patrón.

MORDEL: ¿De cuántos meses está el trigo?

EL HOMBRE: Sembrado en Todos los santos. Estamos cerca de carnavales. 
MORDEL: Bueno. Iré a verlo dentro de una semana. De todos modos, el terreno es ya mío. ¿Estamos conformes?

EL HOMBRE: Patrón es tu terreno.

MORDEL: Bueno[...] ¡Anda con Dios, buen hombre!... ¡Saludos a la Challa. (La pareja vase, el hombre por delante y paso a paso, con la garrafa en alto; la mujer, atrás, sosteniéndolo por la espalda” (Vallejo, 1996, p. 57, destacado añadido).

Cerrado el negocio de adquisición de tierras, surge la pregunta sobre qué llevó a esta pareja de indígenas a realizar un trueque que se podría calificar, inicialmente, como desigual o, al menos, desventajoso. En primer lugar, se dirá que, a través de esta escena, Vallejo actualiza la fascinación que mostró la población indígena desde la llegada de los españoles por productos que bien pueden ser considerados baratijas. ${ }^{7}$ La diferencia entre el intercambio que acontece en la obra de Vallejo frente al intercambio narrado por los cronistas e historiadores es que en estos el intercambio era entre objetos igualmente baladís: adornos de oro frente a baratijas de cristal. Mientras que en la propuesta de Vallejo, se observa la depreciación que el hombre indígena muestra por un producto que, en la visión occidental utilitaria y productiva, tendría más valor: el terreno de trigo.

Lo importante de esta escena y que se debe resaltar es el hecho de que si bien la pareja de indígenas es seducida por Mordel y compañía, es la participación activa de la población indígena en el trueque. Un trueque a todas luces occidentales desigual. Según Ballón, en la perspectiva ideológica con la que Vallejo va articulando su pieza teatral, apela a obtener de los lectores o espectadores una sanción que repruebe el sistema capitalista de la sociedad, cuyo atributo es el usufructo del trabajo de los dominados. No obstante, y a pesar de Vallejo, se cree que este intercambio tiene que ver con otras estructuras epistemémicas en la interrelación entre dominados y dominadores, de ahí la referencia al "origen" de esta transacción que siempre ha sido abordada desde una perspectiva misericordiosa del receptor occidental.

\footnotetext{
${ }^{7}$ La referencia al trueque de oro por cuentas de colores y otras "chucherías" se puede hallar desde las primeras "relaciones" escritas por Cristobal Colón.
} 
Vallejo justifica, a través de la participación de los vendedores, es decir de Mordel y El Comisario, la fascinación mimética del indígena en el deseo de poseer un producto que, en principio, es impropio de su condición social y racial:

MORDEL, en voz alta: Comisario, estamos de acuerdo: ¡un pobre terreno de trigo no vale una garrafa azul como el cielo! ¡Pero, a lo hecho, pecho! No me pesa.

EL COMISARIO: Don Mordel, allá usted...

MORDEL: Date prisa, Orocio... ¡Una garrafa espléndida, que sólo los patrones tienen en sus casas! ¿Verdad, Comisario?

EL COMISARIO: Los patrones... y también los obispos. ¡Los obispos también tienen garrafas azules como el cielo! (Vallejo, 1996, p. 56).

Al indígena no se le da la voz para que sea él quien exprese por qué "cae" en la seducción. No obstante, Vallejo hace dos concesiones: una dramatúrgica y la otra performativa; le otorga al indígena determinación para cerrar el negocio ("Patrón es tu terreno"); asimismo, le otorga una actitud corporal que "explica" su determinación: una actitud sacra ante la posesión del objeto. Esto es, el hombre indígena no solo adquiere la garrafa porque se trate de un objeto de los "patrones", es decir, no solo porque se trate de un amuleto que le asegura el cambio social por el solo hecho de poseerlo y que, se insiste, no le es propio. Se trata más bien, de poseer un objeto sublimado, en otras palabras, se trata de poseer un objeto que de un lado lo desterritorializa de su lugar asignado por la injusta distribución socioeconómica: la tierra; y de otro, le permite territorizarse en un lugar menos terrenal, pero igualmente material: el sacro imperio de la contemplación estética.

De acuerdo a Gebauer y Wulf (1995) el poder de la mímesis radica en las imágenes que estas evocan, puesto que se generan en un mundo o dimensión estética. Las imágenes de hecho tienen una existencia material, pero lo que representan no es más que una parte integral de la realidad empírica. La mímesis pertenece a un orden no empírico del conocimiento, por lo que las imágenes producen conexiones entre el individuo y la realidad empírica, conexiones que tienen que ver con el Mythos de saberse y narrarse humano; con el Mythos de narrarse en la compra de aquella garrafa. 
Como se vio, Vallejo ofrece, ante la activa contemplación estética del indígena, una salida desde la perspectiva enteramente mythica o humana. Mientras que la fascinación por el poder de los "patrones", que también expresan Acidal y Mordel, se circunscriben en una mímesis colonial. Ellos, desde el inicio de la obra, saben que su prosperidad depende de su capacidad para mimetizarse con la "buena sociedad" de aquel paraje andino, con los objetos que esta "sociedad" de patrones, obispos y presidentes posee: el dominio de la palabra tanto escita como performada.

En la pieza vallejiana, el entramado se activa cuando los hermanos Colacho son invitados a la casa del Presidente de la diputación para un almuerzo. Invitación a la que tienen que responder según las modales y costumbres de la época, es decir, una respuesta escrita:

MORDEL: ¿Dónde hay papel, del bueno, para contestar la tarjeta y enviar la respuesta, antes de la hora de la comida?

$[\ldots]$

ACIDAL, recordando de pronto algo: ¡Hombre!... Ahí hay un modelo de carta, en el libro primero de la escuela... (De entre unos paquetes, saca y desempolva un librejo desencuadernado y busca una página) ¡Imponente! ¡Como pedrada en ojo de boticario!

[...] empieza a copiar del modelo.

ACIDAL, agachado: ¿Cómo se escribe "honra"?

MORDEL: "Honra", sin hache.

ACIDAL: Ya lo sé. Pero ¿con una o dos erres? (Silabea, martillando sobre la "ra" de “honra”) ¡Hon-rrra!... Despues de n, una sola erre, me parece. Ooon-rrra... Sí.

MORDEL: "Honra" se escribe con una sola erre, desde luego, pero ponle dos o tres, para que no vayan a pensar que es $\operatorname{avaricia}^{8}$ (Vallejo, 1996, p. 37).

Mediante esta disparatada corrección ortográfica, Vallejo pone en evidencia, una vez más, el factor diferenciador mimético entre las clases subalternas. Gebauer y Wulf nos recuerdan que cuando se le otorga un significado al mundo mimético como opuesto a la

\footnotetext{
${ }^{8}$ Enrique Ballón reproduce este pasaje para ejemplificar el habla "motosa" propia de la diglosia andina (Ballón, 1988, p. 429-430). Este modelo de habla, junto a otros que cita Ballón, tendrían que ver con "los valores axiológicos vigentes en las estructuras contractuales y polémicas que definen la comunicación en la vida cotidiana del pueblo peruano (como resultado de la colonización española y la política asimilacionista de la educación nacional)” (1988, p. 435).
} 
realidad histórica, el poder de uso político de los signos se ve incrementado, así como el poder de depender de los signos se intensifica (1995, p. 318). Por lo tanto, cuanto más dominio y conocimiento se tiene de los mecanismos miméticos de representación, más poder se puede acumular. En la pieza de Vallejo, estos mecanismos de representación colonial son la escritura y los protocolos de urbanidad. ${ }^{9}$ Tecnologías que los futuros presidentes de América deben ir aprendiendo y adquiriendo si quieren seguir escalando social, política y económicamente.

\section{La moderna presidencia es una farsa colonial}

Los hermanos Colacho, a lo largo del tercer y último acto, acompañados de sus asesores Llave y Trozo, ensayan el modo en cómo tienen que comportarse y expresarse cuando lleguen a ocupar la presidencia. El ensayo para presidente del tercer acto tiene a los hermanos intercalándose en el cargo presidencial. Cuando no están en el sillón presidencial, asumen roles subalternos y se suman a los roles que Llave y Trozo también cumplen. Veamos el último ensayo:

LLAVE: Para acabar, la escena de la entrevista con el enemigo (consulta la hora) ¡Más dela una!

MORDEL: ¿Conmigo en la Presidencia?

LLAVE: No. Ahora con don Acidal. (Retirándose del lado de la puerta del foro) Voy a anunciar... (Acidal sigue ante su despacho presidencial. Mordel retorna a la puerta de la derecha y Trozo espera, junto a Llave).

EL AYUDANTE anuncia: Excmo: Señor, acaban de traer al General Ñaton, que cayó preso ayer. Usted había ordenado...

ACIDAL, presidente, tras una reflexión: Sí. Que me lo traigan ante mí inmediatamente (Llave figura que se retira. Pausa)

EL AYUDANTE anuncia: El señor Prefecto de Policía.

TROZO, en el papel del Prefecto, simula que entra: Excmo. Señor, el General Ñatón está en la antecámara.

EL PRESIDENTE: Que pase. (Pausa)

\footnotetext{
${ }^{9}$ Otro de los mecanismos diferenciadores en la pieza vallejiana es el manejo del cálculo o las matemáticas.
} 
LLAVE: Una silla hará del Ñatón. (Cogiendo una silla y colocándola en el centro de la pieza, frente a Acidal) ¡Está!... (Mirando la silla). El viejo Ñatón viene las manos atadas a la espalda, sucio, en traje de campaña, sin kepi, tránsido. La rabia y la amargura del vencido crispan su rostro y arrancan de sus ojos una llama salvaje... (Todos miran la silla)

TROZO: Una vez Natón ahí, un silencio mezcla de curiosidad y de estupor, impera en el despacho presidencial, que está lleno de grandes personajes oficiales. Nadie habla ni se mueve. (En efecto, todos escenifican dicho ambiente)

LLAVE, mirando la silla: Natón, puesto frente a frente con el Presidente, baja los ojos. (A Acidal) Usted le observa con rencor... (Acidal observa la silla con rencor) MORDEL: Ya. Ahora puedes hablarle.

EL PRESIDENTE, a la silla, airado: ¡Miserable! ¡Traidor a la Patria! ¿Qué fines la han guiado para conspirar contra mi gobierno?... ¿Pretendía usted volver a la presidencia, para mancharla de nuevo con la sangre inocente del pueblo y para echarse otros millones al bolsillo?... ¡Conteste! (Al Ayudante) Desátenle las manos. (Llave figura cumplir con la orden). El presidente saca entonces un revólver del bolsillo y se lo da al prisionero) Coja usted mi revólver... (Pone el arma sobre la silla y se ofrece a Ñatón como blanco) ¡Mátame!... Pedía usted mi cabeza. Y ¡bien! aquí la tiene usted a su alcance... ¡Tire!... (Ñatón, sigue inmóvil. El Presidente saca entonces otro revólver y, apuntando al pecho del prisionero, le desafía) ¡Pues entonces, de hombre a hombre! ¡Apunte! ¡Tire!... ¡Al que queda de pie, la presidencia!... (Sensación en el despacho presidencial) ¡Uno!... ¡Dos!... ¡Levante su arma! ¡Apunte!... ¡Cómo! ¿Dónde está es valentía?... (Y como Natón no se mueve, el Presidente le dice con desprecio) ¡Cobarde!... Devuélveme esa arma... (Recoge violentamente el arma de la silla y ordena) Atadle otra vez... (La orden se ejecuta. El Presidente ruge) ¡Cobarde!... (Figura que le arranca las charreieras) ¡No las merece!... ¡Soldado indigno!... (En fin, figura que le escupe) ¡Llevadle!... ¡A los aljibes!... (La puerta del foro se abre bruscamente y el General Tequila penetra, seguido de varios oficiales y tropa; el teniente Millar viene entre ellos. Los Colacho y sus secretarios se quedan paralizados) EL GENERAL TEQUILA ordena a la tropa, señalando de uno en uno a Acidal, a Mordel, a Llave ya Trozo: ¡Al Presidente de la República! ¡Al secretario! ¡Al 
ayudante! ¡Y al Prefecto de Policía! ¡Las esposas a los cuatro!... (La tropa ejecuta la orden y los cuatro hombres entregan las manos mansamente) iY fusiladlos antes de la aurora!...

VOCES de muchedumbre, mientras baja despacio el telón: ¡Abajo la revolución! ¡Abajo el imperialismo norteamericano! ¡Viva el Presidente Palurdo! FIN DE LA FARSA (Vallejo, 1996, p. 140-142).

Luego de reproducir este extenso pasaje es importante, dirigirnos al título completo de la pieza de César Vallejo: Colacho Hermanos o Presidentes de América. El primer título, según Ballón, tiene que ver con el "rótulo de una sociedad comercial" (1988, p. 436) que, por anteceder al segundo título, lo funda. En ese sentido, habría un acto social y comercial que funda y pauta el ejercicio político.

Paralelamente al proceso de ascenso económico de los hermanos Colacho, se observa su ascenso como dirigentes políticos, que si bien esta signada por el original temor de Mordel, consciente de sus orígenes socio-raciales y económicos, este tiene que someterse a la dictadura del imperio que va programando la ocupación de lugares de administración del poder político. Quien desde un principio sí muestra su apetito político es Acidal. Apetito que se sostiene, como ya se vio, en su deseo mimético de poseer y manipular los objetos de los "patrones".

En tal sentido, en el segundo enunciado del título, es posible comprender la potencia con la que acaba la pieza vallejiana: "Fin de la farsa", pues la "farsa" de la que habla Vallejo tiene se relaciona tanto con la naturaleza del género teatral que culmina en escena y el texto dramático como con el ensayo y, por lo tanto, la inauténtica y aparente representación de la usurpación del máximo cargo político por parte de los mellizos Colacho, Mordel y Acidal.

Los programas para llegar a ocupar los distintos cargos políticos son ilustrados por Vallejo desde la satirización de los mecanismos de dominio como la participación en jornadas “democráticas", la institucionalidad política asentada en risibles reglas de urbanidad y etiqueta, en engendros de manipulados actos de revolución y golpes de estado, en otras palabras en fársicos actos de representación política.

Comicidad política que de acuerdo a Natalia Gómez - en su análisis del guión fílmico Presidentes de América - es heredera del cine mudo en especial el desarrollado por Charles 
Chaplin y del teatro ruso. Film que de acuerdo a Gómez “critica y ridiculiza los gobiernos de Oscar Raimundo Benavides y Luis M. Sánchez Cerro así como cualquier otra presidencia que transplante sistemas advenedizos contra el desarrollo de una economía nacional.” Sistemas que, desde nuestra perspectiva tienen que ver con la caracterización de la clase política peruana como venida a menos o heredera de la colonialidad.

Para Ballón a partir de esta pieza se inicia en el teatro peruano: "la deflagración del discurso histórico peruano tradicional, su parodia crítica, lúcida y enérgica" (1988, p. 448). Parodia que si bien constituye un mecanismo propio de la estética realista y comprometida en que Vallejo se adscribe, ha diferenciado el componente mimético colonial de la mímesis mythica.

\section{Referencias bibliográficas}

Alcántara Mejía, José. (2002). Teatralidad y cultura: hacia una estética de la representación. México D. F.: Universidad Iberoamericana, Ciudad de México.

Aldana Hidalgo, Julio. (2015). Conflicto minero y subalternidad en El Tungsteno de César Vallejo (Tesis de maestría en Estudios Culturales). Lima: PUCP. Recuperado de http://tesis.pucp.edu.pe/repositorio/handle/123456789/6499

Ballón, Enrique. (1988). "El efecto Ideológico en el teatro de César Vallejo: Colacho Hermanos o Presidentes de América”. Cuadernos Hispanoamericanos, (454/455), 423-448.

Colón, Cristobal. (2012). Diario, cartas y relaciones: antología esencial. Buenos Aires: Ediciones Corregidor.

de Vallejo, Georgette. (2012). Vallejo: Allá ellos, allá ellos, allá ellos! Lima: Universidad Alas Peruanas.

Estermann, Josef. (2014). “Colonialidad, descolonización e interculturalidad. Apuntes desde la Filosofía Intercultural”. Polis (07176554), (38), 2-15. doi:10.4000/polis.10164.

Frye, Northop. (1977). Anatomía de la crítica. Caracas: Monteavila.

Gómez, Natalia. (2015). La sombra de Charles Chaplin en César Vallejo. Recuperado de https://pendientedemigracion.ucm.es/info/especulo/numero39/chaplinv.html

Gebauer, Gunter y Wulf, Christoph. (1995). Mimesis: culture, art, society. Berkeley California: University California Press. 
Klein, L.B. (1974). “Antiimperialismo y literatura en el caribe (1898-1933)”. Anales de literatura hispanoamericana, (2/3), 209-222. Recuperado de https://revistas.ucm.es/info/index.php/ALHI/article/view/ALHI7374110209A

Kozel, Andrés; Grossi, Florencia y Moroni, Delfina. (2015). El imaginario antiimperialista en América Latina. Buenos Aires: CLACSO/Centro Cultural de la Cooperación Floreal Gorini.

Podesta, Guido. (1987). "La Nueva Estética Teatral De César Vallejo”. Discurso Literario: Revista De Temas Hispanicos, (4.2), 509-523.

Ricoeur, Paul. (1995). Tiempo y narración. México: Siglo XXI.

Vallejo, César. (1996). “Colacho hermanos”. Tres obras dramáticas. Lima: PUCP.

Vallejo, César. (1979). “Colacho hermanos”. Teatro Completo, Vol. II. Lima: Pontificia Universidad Católica del Perú. Lima.

Vara, Ana María. (2013). Sangre que se nos va. Naturaleza, literatura y protesta social en América Latina. Sevilla: CSIC.

\section{(c) (†) $९$}

Esta obra está bajo una licencia de Creative Commons Reconocimiento-NoComercial-

$\underline{\text { SinObraDerivada } 4.0 \text { Internacional }}$ 